\title{
Response of shoot growth and gas exchange of Picea abies clones to rain acidity and the addition of ions
}

\author{
P. Van Elsacker and I. Impens
}

Department of Biology, University of Antwerp (UIA), Universiteitsplein 1, B-2610 Wilijk-Antwerpen, Belgium

\section{Introduction}

The novel forest decline observed in Europe and the U.S.A. may be caused by several factors, among them, air pollution is thought to be very important. Interference of pollutants with the ecophysiological performance of forest trees needs to be investigated in order to understand the actual working mechanisms. The aim of this study was to examine the effect of acidic wet deposition on $\mathrm{CO}_{2}$ exchange, needle conductance and shoot growth of Norway spruce, particularly the effect of acidity and the addition of a realistic ionic mixture to simulated acidic precipitation.

\section{Materials and Methods}

Four year old potted plants of 3 Belgian Picea abies (L.) Karst. clones were grown in a greenhouse (clone number 1007, 1011 and 1019). The plants were sprayed 3 times a week throughout the growing season with a hand pumped sprayer. The 4 treatments were: $\mathrm{pH} 5.6^{-}$and 5.6+: de-ionized water in equilibrium with the atmospheric $\mathrm{CO}_{2}$ pressure, resp. without $(-)$ and with $(+)$ the ionic mixture mentioned below; $\mathrm{pH} 4.0^{-}$and 4.0+: same as $\mathrm{pH} 5.6$ but the solution was acidified to $\mathrm{pH} 4.0$ with a mixture of sulfuric and nitric acids $\left(\mathrm{SO}_{4}^{2-} / \mathrm{NO}_{3}^{-}\right.$ weight ratio $=2.4$ ). lonic concentrations in $\mathrm{mg} /$ were: $4.50 \mathrm{SO}_{4}^{2-}, 2.00 \mathrm{NO}_{3}^{-}, 1.20 \mathrm{NH}_{4}^{+}$, $0.99 \mathrm{Na}^{+}, 1.45 \mathrm{Cl}^{-}, 0.30 \mathrm{~K}^{+}, 0.60 \mathrm{Ca}^{2+}$, $0.30 \mathrm{Mg}^{2+}$ and $0.40 \mathrm{HSO}_{3}^{-}$(Van Elsacker et al., 1988).

Gas exchange was measured on fully grown current year shoots during the summer. $\mathrm{CO}_{2}$ exchange rate (CER) was measured at PPFD saturation with a portable, closed-loop system (Van Elsacker and Impens, 1986). The number of data was 12 measurements $x 4$ treatments $x$ 4 (parts of) days. Needle conductance $(G n)$ was measured with an automatic diffusion porometer developed at the laboratory (procedure comparable to Delta-T porometer). Data were calculated on a needle dry weight basis ( $\left.\mathrm{gdw}^{-1}\right)$. The number of $G$ data was 13 measurements x 4 treatments $\times 3$ (parts of) days for clone 1011, and $11 \times 4 \times 4$, respectively, for the other clones. To analyze the gas exchange data, a 3way analysis of variance with the factors $\mathrm{pH}$, ions $(-$ or + ) and day was used; the factor 'day' allowed for temporal, environmental and ecophysiological variations.

The length of top and lateral current year shoots of 13 plants per treatment and per clone was measured every 3-4 d from bud break (midMay) until growth had stopped (July, total of 13 measurement d). A non-linear regression procedure was used to fit a logistic growth function. 


\section{Results}

Treatment means, pooled for the whole summer, of net $\mathrm{CO}_{2}$ exchange (CER) and needle conductance $(G n)$ of the 3 clones are shown in Fig. 1a, b. $\mathrm{CO}_{2}$ exchange rate was reduced for all clones at $\mathrm{pH} 4.0^{+}$ as compared to the other 3 treatments, a significant $\mathrm{pH} \times$ ions interaction was found for each clone. The Newman-Keuls test resulted in the following significant differences between the treatment means: 1) clones 1007, 1019: 4.0+ 5.6- 5.6+4.0-; clone 1011: $4.0^{+} 5.6^{-} 4.0^{-} 5.6^{+}$(sorted from low to high, underlined treatments are not significantly different at $P<0.05$ ).

The response of the conductance for water vapor $(G n)$ to simulated precipitation differed between clones. Gn of clone 1007 was not affected: no significant effect of $\mathrm{pH}$, ions or any interaction was observed. Clone 1011 showed a reduced $\mathrm{Gn}$ at $\mathrm{pH}$ $4.0^{+}$and a significant interaction of $\mathrm{pH} \times$ ions. The Newman-Keuls test yielded the following: $4.0^{+} 5.6^{-} 5,6^{+} 4.0^{-}$.

The conductance of clone 1019 was also reduced at $\mathrm{pH} 4.0^{+}$and a significant interaction of $\mathrm{pH} x$ ions $x d$ was found. The Newman--Keuls test was not significant at $P<0.05$ for the treatment means.

The growth analysis of clone 1007 is shown in Fig. 2a, b. The mean length of the top shoot (Fig. 2a) is plotted against time in days (d $1=1$ May). The logistic growth function: $f(t)=A /[1+\exp (b-k \cdot t)]$, was very significant $(R>0.72)$ but there were no differences of the parameter estimates between the treatments $(P<0.05)$. Typical values were: $A=142-160 \mathrm{~mm}$, $b=5.7-6.9, k=0.13-0.15 d^{-1}$. The point of inflexion, where half of the final length was reached, was on d 44-48 $(=b / k)$. Absolute growth rates were also very similar as can be deduced from the slopes of
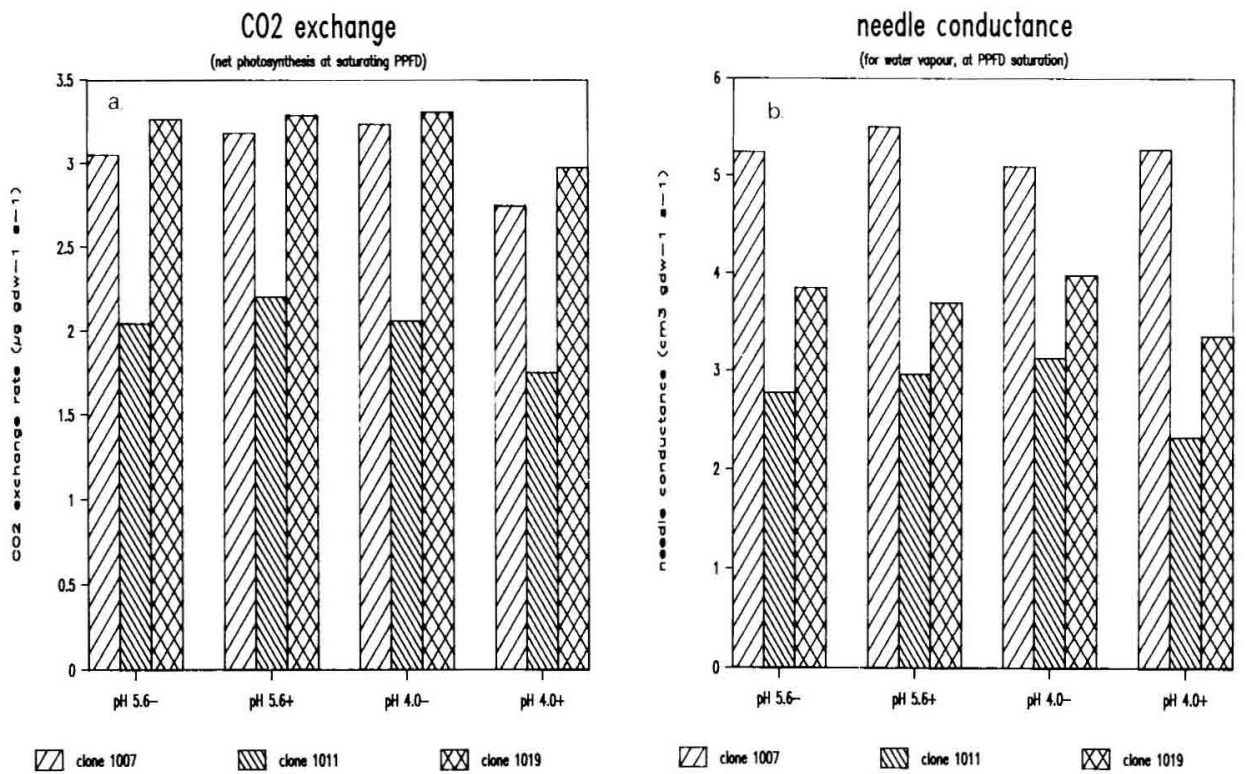

Fig. 1. Treatment means of (a) $\mathrm{CO}_{2}$ exchange rate and (b) needle conductance at saturating PPFD of the tree clones. 

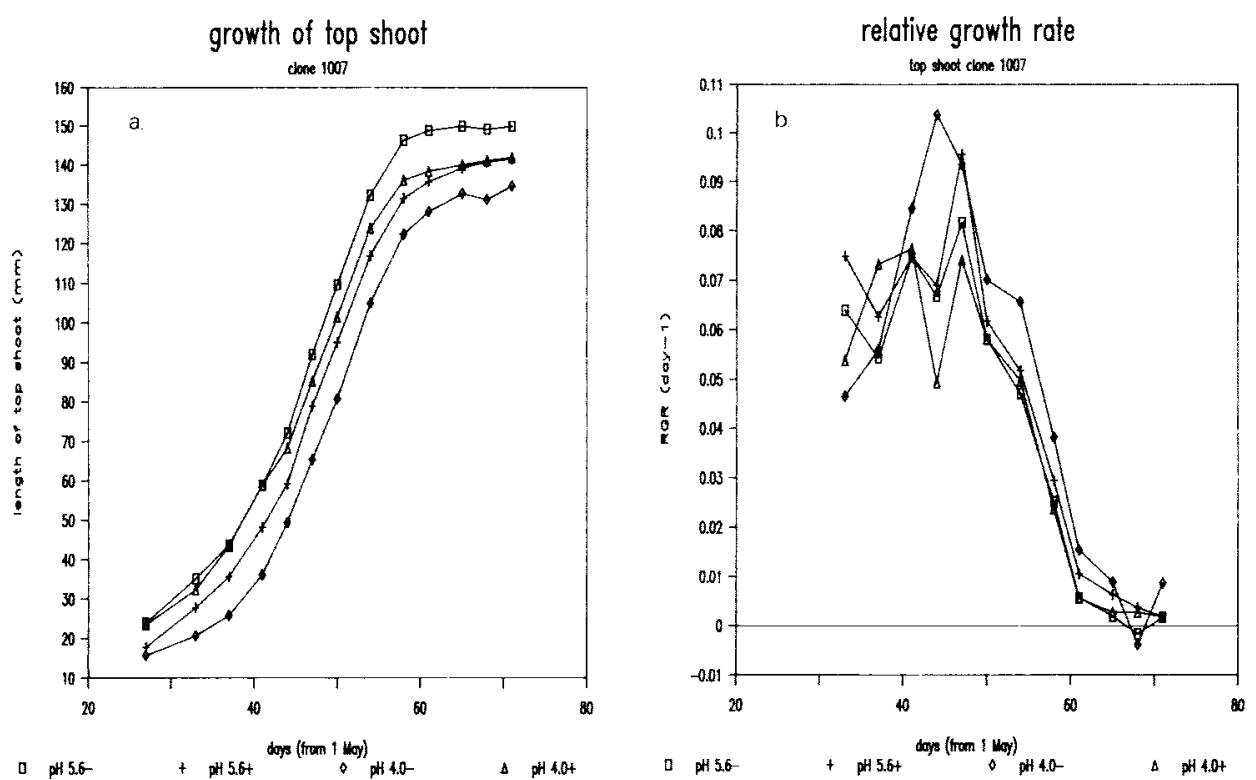

Fig. 2. Growth of top shoot of clone 1007: (a) changes in mean shoot length with time; (b) changes in mean relative growth rate with time. Lines only connect means of each treatment.

the curves in Fig. 2a. Relative growth rates $(R G R)$ are plotted in Fig. 2b. The lines connecting the RGR values for different time periods of each $\mathrm{pH}$ treatment cross one another, there were no clear differences between the 4 treatments. Similar results (not shown here) were obtained for top shoot growth of clones 1011 and 1019, the latter showing lower final lengths $(A=112-136 \mathrm{~mm})$, lower $b$-values $(b=4.8-5.7)$ and inflexion points on $\mathrm{d}$ 35-38. The growth of lateral shoots also did not show clear differences between the $\mathrm{pH}$ treatments.

\section{Discussion and Conclusion}

The reduction of $C E R$ and $\mathrm{Gn}$ at $\mathrm{pH} 4.0^{+}$ and the significant $\mathrm{pH} \times$ ions interaction suggest a synergism between increasing acidity and the addition of the ionic mixture. The effect of acidic rain on the $G_{n}$ of clone 1019 seemed to depend upon environmental and/or ecophysiological conditions (interaction $\mathrm{pH} x$ ions $x \mathrm{~d}$ ). A reduction of the photosynthetic capacity may have consequences for growth and production of forest trees, as observed for poplar (Van Elsacker et al., 1988). However, length growth of top (and lateral) shoots in this experiment was not obviously changed by any simulated (acidic) precipitation treatment.

\section{Acknowledgments}

This work is supported by the Commission of the European Communities, project no. EV4V0017-B (GDF). The authors wish to thank Dr. A. Nanson (Forestry Experimental Station, Groenendaal-Hoeilaart) for the clones. 


\section{References}

Van Elsacker P. \& Impens I. (1986) Direct effects of simulated acid wet deposition on gas exchange of Norway spruce. In: Direct Effects of Dry and Wet Deposition on Forest Ecosystems - in Particular Canopy Interactions. Air Pollution Research Report 4. Commission of the European Communities. Workshop Proceedings, Lökeberg, 19-23 October 1986, pp. 122-131

Van Elsacker P., Martens C. \& Impens I. (1988) Direct effects of acid wet deposition on photosynthesis, stomatal conductance and growth of Populus cv. Beaupré. In: Air Pollution and Ecosystems. (Mathy P., ed.). D. Reidel Publishing Company, Dordrecht, Holland, pp. 728-733 